\title{
Knowledge transfer to industry: how academic researchers learn to become boundary spanners during academic engagement
}

\author{
S. A. M. Dolmans ${ }^{1} \cdot$ B. Walrave ${ }^{1}$ (D) $\cdot$ S. $\operatorname{Read}^{2} \cdot$ N. van Stijn ${ }^{1}$
}

Accepted: 7 September 2021 / Published online: 17 September 2021

(c) The Author(s) 2021

\begin{abstract}
Research on academic engagement and technology transfer or commercialization offers important insights into the relationship between characteristics, activities and abilities of individual academic researchers, with outcomes such as successful technology transfer and commercialization. In particular, the activity of boundary spanning proves central in the successful transfer and commercialization of university developed technologies. However, the process by which academic researchers become boundary spanners remains relatively unexplored. This investigation serves to shed new light on the matter. We draw on an in-depth case study of a large European publicly funded initiative, directed to stimulate industry adoption of a university-developed technology across Europe. Our rich dataset is a result of following the project from start to finish, triangulating from multiple sources over a three-year period. Our analyses offer novel insight into the role of perspective taking as a mechanism both enabling academics to understand knowledge boundaries faced during engagement activities and a critical input to developing and improving boundary spanning abilities. Our findings offer important implications for research on academic engagement and technology commercialization.
\end{abstract}

Keywords Technology transfer $\cdot$ Academic engagement $\cdot$ Dynamic perspective $\cdot$ System dynamics $\cdot$ Boundary spanning

\section{Introduction}

Technology commercialization can be considered the managed process by which technological ideas or knowledge are transferred from the research laboratory to the marketplace (Klofsten et al., 2010; Urbano \& Guerrero, 2013). Of particular interest are university developed technologies, which are a driver of economic development by creating financial as well as societal value (Lockett et al., 2005; Shane, 2004; Siegel et al., 2003). Examples

\section{B. Walrave}

b.walrave@tue.nl

1 Eindhoven University of Technology, Eindhoven, The Netherlands

2 Willamette University, Salem, OR, USA 
of high-impact university developed technologies and subsequent applications include the Computed Tomography (CAT) scan, solar power and optical disks (see, e.g., the well-documented case study by Rosenkopf \& Nerkar, 2001).

Within the process of university technology commercialization, the individual academic researcher is often a core component (Cohen et al., 2002; Miller et al., 2018; Perkmann et al., 2013) as (s)he typically needs to engage in transferring highly specialized knowledge across boundaries (Kidwell, 2014). When an academic offers expertise to suggest solutions to a collaborating organization (Perkmann et al., 2013) it constitutes academic engagement. Underlying activities may include formal research, licensing and consulting, or informal advice and networking (Bonaccorsi \& Piccaluga, 1994; D'Este \& Patel, 2007; MeyerKrahmer \& Schmoch, 1998; Perkmann \& Walsh, 2008; Perkmann et al., 2013). The individual abilities of academic researchers (hereafter academics) which enable these activities connect with important outcomes such as knowledge transfer and technology commercialization (Calcagnini \& Favaretto, 2016).

Individual abilities, however, are developed over time based on feedback and learning through repeatedly engaging in an activity. So, while individual characteristics may influence initial level and/or form of academic engagement, the activity itself may serve as a basis for learning and new abilities. Such ability development may become evident in behaviors, actions and attitudes of academics over time. Study in the area of academic engagement and technology commercialization devotes significant attention to questions around the characteristics of academics, but the abilities individuals may develop during such activities remain relatively unexplored. We aim to begin to address this gap. A better understanding of ability development during academic engagement promises to shed new light on the relationship between individuals and relevant outcomes to the knowledge transfer process.

We begin our investigation with a focus on academic engagement and boundary spanning ability. By means of a longitudinal, in-depth case study, we describe relevant patterns that academics exhibit over time while engaged in a European project aimed at stimulating industry adoption and commercialization of a university technology (Eisenhardt \& Graebner, 2007). Our study is designed around the following research question: How do academics become boundary spanners during academic engagement? We find that academics who engage in knowledge transfer activities develop boundary spanning ability, by engaging in perspective taking. We contribute to literature on academic engagement and (university) technology transfer and commercialization by explaining how academic engagement builds boundary spanning ability over time. Our insights also contribute to theory and future research in the boundary spanning and perspective taking discussions.

\section{Theoretical background}

Many universities assume an additional role, beyond education and generation of knowledge, to include commercialization of academic research (Shane, 2004; Youtie \& Shapira, 2008). Often termed technology transfer, the activity offers academics the potential of impact through market acceptance of technologies and innovations created at the university (Markman et al., 2008; Perkmann et al., 2013). Universities support commercialization through science parks, technology transfer offices (TTOs) and incubators (Clarysse et al., 2005) to name a few. With such opportunities, commercialization activities also present new challenges to academics, adding academic engagement to an already diverse list of job responsibilities. 


\subsection{Academic engagement}

Academic engagement can be defined as "knowledge-related collaboration by academic researchers with non-academic organizations" (Perkmann et al., 2013: 424). In that same work, the authors go on to detail "interorganizational collaboration instances, usually involving 'person-to-person interactions' (Cohen et al., 2002, referenced in original), that link universities and other organizations, notably firms ... generally the partners pursue goals that are broader than the narrow confines of conducting research for the sake of academic publishing, and seek to generate some kind of utility for the non-academic partners" (2013: 424). There are variations on the term, with some authors calling the activity "informal technology transfer" (Grimpe \& Fier, 2010; Link et al., 2007), despite the many paid and institutionally organized arrangements (Perkmann et al., 2013). Perkmann et al. offer significant color on what actually happens in academic engagement, summarized as "formal activities such as collaborative research, contract research, and consulting, as well as informal activities like providing ad hoc advice and networking with practitioners" (2013: 424).

Academic engagement is directly influenced by organizational level factors such as university/department quality (negatively) (e.g., Ponomariov, 2008; Ponomariov \& Boardman, 2008) and group-level norms (positively), connecting individual characteristics with academic engagement activity (Louis et al., 1989). Affiliation with specific academic disciplines influences academic engagement, as applied fields of research engage with industry more frequently (Bekkers \& Freitas, 2008; Martinelli et al., 2008). Type of knowledge transfer channel also impacts academic engagement. Biomedical and chemical engineering, for instance, more often utilize patents and licensing than other areas where knowledge transfer may be less formal (Bekkers \& Freitas, 2008). Furthermore, individual characteristics such as gender, seniority/tenure, and previous scientific success (e.g., Matthew effect; Merton, 1968) are related to academic engagement (Bercovitz \& Feldman, 2007; Link et al., 2007) and university support for commercialization (Dolmans et al., 2016; Shane et al., 2015). Individual ability also influences academic engagement. For instance, the ability to mobilize resources or obtain government grants - signaling the ability to attract funds in general-is positively related to engagement and collaboration with industry (Perkmann et al., 2013).

One interesting finding from the literature on academic engagement and technology commercialization is that the activity is performed by a small subset within the population of academics. In an article entitled " Repeat commercializers,' the 'habitual entrepreneurs' of university-industry technology transfer" the authors find " $12 \%$ of the faculty who are repeat commercializers account for $80 \%$ of the commercialized innovations" (Hoye \& Pries, 2009: p. 682). One of the key activities researchers frequently involved in commercialization undertake is boundary spanning, bringing knowledge back and forth between academic and industrial environments (Hayter et al., 2020; Hoye \& Pries, 2009; Mangematin et al., 2014). We conduct a brief review of boundary spanning theory next.

\subsection{Boundary spanning}

Boundary spanning can be defined as an activity performed by individuals who translate and frame information, promoting knowledge flow across communities (Aldrich \& Herker, 1977; Brown \& Duguid, 1998; Teigland \& Wasko, 2003). A knowledge 
boundary can be considered the limit, or border, of an actor's knowledge base in relation to a different knowledge domain (Hawkins \& Rezazade Mehrizi, 2012). Three types of boundaries are identified in the literature, describing increasing novelty and commensurate complexity: (a) syntactic, (b) semantic, and (c) pragmatic (Carlile, 2002, 2004). A syntactic boundary is characterized by actors that share a common lexicon (low novelty) but have a difference in the amount of knowledge. A semantic boundary is characterized by a difference in how actors interpret meanings of the same concept. That is, there is no common lexicon, due to novelty, that makes differences and dependencies unclear and meanings ambiguous. A pragmatic boundary occurs when different interests among actors arise due to novelty, that need to be resolved before knowledge may be effectively transferred.

Boundary spanning theory suggests knowledge boundaries become increasingly challenging for the boundary spanner as novelty increases (Carlile, 2002, 2004; Carlile \& Rebentisch, 2003). Thus, different boundaries correspond to different boundary spanning behaviors or capabilities to 'overcome' the knowledge boundary. A syntactic boundary starts from a common lexicon and can be overcome using a straightforward knowledge transfer approach. Overcoming a semantic boundary demands the creation of common meaning through a more complex process of translation. A pragmatic boundary necessitates the creation of common interest to share and access knowledge, which requires both practical and political effort, employing an intricate transformation approach.

\subsection{Boundary spanning abilities}

Boundary spanning theory implies various abilities are required to effectively manage different types knowledge boundaries (Carlile, 2004) and corresponding variations in uncertainty of the environment (Leifer \& Delbecq, 1978; Leifer \& Huber, 1977). Individual characteristics are theorized to enable boundary spanning abilities (Tushman \& Scanlan, 1981a, 1981b). In a book chapter summarizing work in the area, Beechler et al. enumerate "traits of integrity, humility, inquisitiveness, and hardiness" as the foundations of boundary spanning abilities at the individual unit of analysis (2004: p. 124). The positive connection with boundary spanning abilities and outcomes such as decision-making performance (Jemison, 1984), buyer-supplier relationships (Zhang et al., 2011), as well as organizational performance, has long been established (Dollinger, 1984). And while researchers argue in support of investigating how boundary spanning abilities come to be (Levina \& Vaast, 2005), limited research has followed the call, providing motivation for our current study.

\subsection{Academics as boundary spanners}

"The success of business incubators and technology parks in university settings is often determined by how well technology is transferred from the labs to their startup firms" (Markman et al., 2005: p. 241). Transferring the specialized knowledge of a focal technology for potential applications in other organizations ultimately comes down to the individual(s) involved (Booz \& Lewis, 1997). Research focused on academics as boundary spanners identifies individual characteristics of interdisciplinary activities and industry orientation as associated with the ability to generate new funding, a key element in the technology commercialization process (Melkers \& Xiao, 2012), as well 
as leadership and resource mobilization abilities (Takanashi \& Lee, 2019) that enable successful commercialization. Consistent with general work on knowledge transfer, boundary spanning plays a key role in technology transfer from the academic environment (Boardman \& Ponomariov, 2009; Hayter et al., 2020; Rogers, 2002; Rogers et al., 1999). And while there are significant efforts to establish technology transfer offices (Huyghe et al., 2014; Lee et al., 2010) and centers (Comacchio et al., 2012), intended to facilitate the process, their effectiveness is equivocal with some academics going around the institutions to accomplish necessary boundary spanning activities (Siegel et al., 2004). When done well, however, the positive results to boundary spanning academics are many. In addition to financial compensation, academics engaged in linking science with industry have access to unique knowledge generated through their interactions (Debackere \& Veugelers, 2005; Sorensen \& Chambers, 2008). Spinoffs generated by academic boundary spanners can offer significant additional financial and opportunity rewards to both individuals and institutions (O'Shea et al., 2005). And more broadly, academic boundary spanners can create positive change in society which stems from their individual activities (Wright, 2014), offering further motivation for our research.

\section{Method}

We selected a longitudinal, in-depth case study approach (Yin, 2017) because of its suitability for exploring our research question (Cunningham et al., 2017; Edmondson \& McManus, 2007). This method enables us to advance theory by gaining a rich understanding of what happens when academics engage with industry and how boundary spanning ability develops over time (Langley, 1999; Yin, 2017). In particular, by drawing on multiple sources of data, we can expose underlying mechanisms and temporal feedbacks that drive boundary spanning ability (Gioia et al., 2013). We work to exploit the method to its fullest, (a) narrating our findings with rich detail, (b) structuring key causal mechanisms over time, (c) developing theoretical aspects of interest, and (d) accumulating implications for future research.

\subsection{Case setting}

Following the principles of theoretical sampling (Eisenhardt \& Graebner, 2007) we draw on a longitudinal, in-depth single case study of a large European publicly funded project directed to stimulate industry adoption of a university-developed technology at the intersection of physics and engineering. We term the project 'NewTech' and tracked its activities, development and progress throughout the full duration of the project (2016-2019). Nine European universities, with scientific expertise in developing and applying NewTech, received dedicated funds to support the dissemination and commercial application of the technology. The academics involved in the project are all experts in NewTech but had little or no experience with academic engagement at the start of the project. This setting, therefore, is particularly suitable for illuminating and describing how engaging in technology transfer and boundary spanning activities relate to boundary spanning abilities (Langley, 1999).

At the start of the project, every one of the nine universities established a 'Support Center' (SC) to facilitate academic engagement. Each SC assigned one or more academics to manage outreach and support activities and transfer of NewTech knowledge to industry 
Table 1 Descriptive data on NewTech project

Description

Dissemination of a university-developed technology at the intersection of physics and engineering for novel (commercial) applications

\begin{tabular}{ll}
\hline Duration & $2016-2019$ \\
Funding & $1,000,000$ Euro \\
Institutions and individuals & 9 European universities, each with a "Support Center" \\
& (SC) \\
& 1 Consulting firm \\
& 1 Industry association \\
& 27 Academic researchers (24 male, 3 female) \\
& 11 Support staff \\
Total industry actors contacted by Support Centers & 237 \\
Total new applied prototypes developed & 50 \\
\hline
\end{tabular}

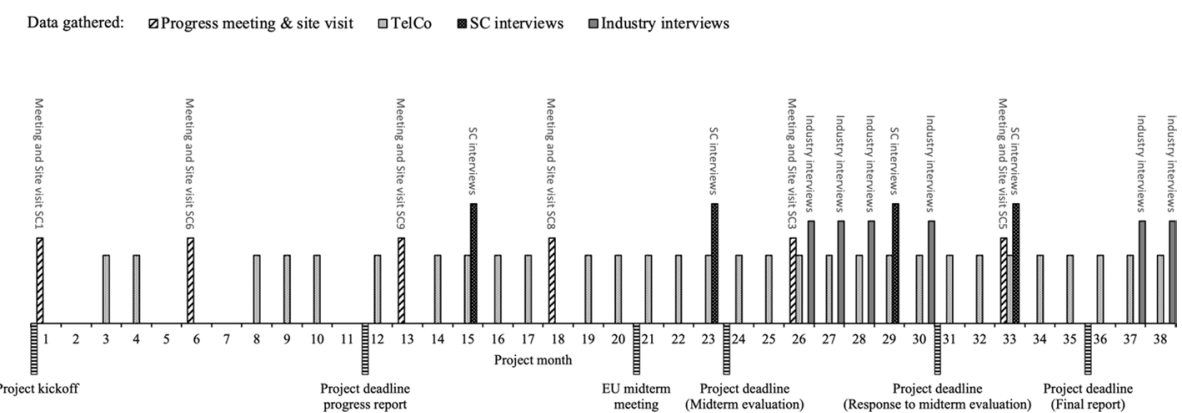

Fig. 1 Timeline of project milestones and data collection milestones by month

actors. Though the project involves a diverse set of stakeholders, our research question directs focus to the academics working to span knowledge boundaries in the engagement effort. Data describing the NewTech project are presented in Table 1.

\subsection{Data and data collection}

Data were collected real-time as the NewTech project unfolded, from the start of the commercialization effort in January 2016 until project completion in March 2019. Seeking broad inferences from the case, primary investigators collected interview data, participant observations, quantitative data and archival data. Figure 1 summarizes the timeline of the NewTech project and the data collection milestones by month over the 38 months of data collection. Interview data consists of semi-structured interactions with the academics running the SCs (24 interviews), industrial actors (30 interviews) and project managers (2 interviews). Each interview was recorded and transcribed verbatim. During the interviews, the academics were asked to elaborate on topics such as their; (a) academic and professional background; (b) experience with the focal technology; (c) experience with academic engagement and technology commercialization activities; (d) role in the project and the SC; (e) knowledge transfer activities and practices as part of the project; and (f) challenges and learning opportunities. Interviews with industrial actors (contacted and supported by 
the SCs) served to triangulate findings (Yin, 2017) relating to the academics' engagement activities, thereby alleviating potential informant bias by obtaining various perspectives (Eisenhardt \& Graebner, 2007). During interviews, industrial actors were asked about their experiences with the type and intensity of engagement approaches used by the academics (e.g., calling, type of information provided) as well as its impact (e.g., did any technology knowledge, and its potential for business, successfully transfer?).

In addition, primary investigators attended monthly project teleconference meetings (TelCo's) and attended and gathered data at seven physical, semi-annual project progress meetings (with site visits) over the course of the project. During those semi-annual meetings all academics involved in the project met to discuss, among other topics, progress, challenges and best practices. All meeting data were recorded and transcribed. These data provide a more complete understanding of the academics' practices, discussions among themselves and the sharing of valuable insights that helped them learn. These meetings also served as opportunities to (in)formally interview project leaders.

The archival data consists of the project proposal, project documents, progress reports, presentations, web articles, emails, and all documentation and materials used by the academics during engagement activities. These data were used to triangulate the findings of the primary interview data and meeting data by validating and strengthening the grounding of the observed patterns (Eisenhardt, 1989; Yin, 2017).

Additional (quantitative) data were collected over the entire course of the project via a custom designed online engagement database where the academics of each SC were required to $\log$ all interactions with industry in real-time. This system resembled an actively maintained customer relationship management database. The academics logged, among many other details, the industrial actors they interacted with, the date and nature of these interactions, the amount and nature of information exchanged, whether the actors showed any interest in the focal technology and potential doubts or concerns expressed by the industrial actors. Overall, the SCs logged 237 scouting activities (each activity typically described by various entry updates over time). This database allowed the primary researchers for this manuscript to further triangulate key findings and identify and contact industrial actors for interviews.

\subsection{Data analysis}

To structure our data analysis, we followed the methodology described by Gioia et al. (2013) and widely employed by management scholars (e.g., Dattée et al., 2018; York et al., 2016). Data analysis was initiated shortly after the start of our data collection efforts and proceeded together with continued data collection, typical for longitudinal, inductive work (Gioia et al., 2013; Langley, 1999). We started with open coding and data-driven sensemaking of primary interview and meeting data, aiming to capture key activities and events in informant terms, including academics' reflections on project features, activities and dynamics, as well as academic engagement approaches and effectiveness. Throughout the 
data collection and analysis process we triangulated emerging findings with archival data and observations from our online engagement database. We worked iteratively to refine key codes and concepts by actively comparing similarities and differences to arrive at a relevant, manageable set of $1^{\text {st }}$ order concepts (Gioia et al., 2013). As coding progressed, we moved to more theoretically abstract analysis in seeking to understand whether and how academics evolved in their engagement approach — reflective of boundary spanning ability. ${ }^{1}$ While seeking to distill theoretical $2^{\text {nd }}$ order themes and aggregate dimensions, our analysis pointed to specific communication patterns that emerged as the academics engaged with industry. As we cycled between emergent data, themes, concepts and relevant literature to see whether our findings had any precedent (Gioia et al., 2013), it became evident that work by Carlile $(2002,2004)$ facilitated an interpretation of the nature of the knowledge boundaries as well as the communication patterns emerging from our data (Langley, 1999). In particular, our $2^{\text {nd }}$ order themes, capturing the academics' communication or engagement patterns, seemed to resemble specific boundary spanning approaches (i.e., syntactic or more semantic/pragmatic boundary spanning approaches, see Carlile, 2002, 2004). As such, we integrated these theoretical concepts along with others that emerged from our data in developing a theoretical understanding of the observed dynamics. The iterative coding procedures and analyses resulted in our data structure, presented in Fig. 2. Figure 2 graphically depicts our progress from raw data to concepts and themes, offering transparency and rigor of our qualitative approach (Aguinis \& Solarino, 2019; Gioia et al., 2013; Pratt, 2009; Tracy, 2010). In Appendix 1 we include significant supporting raw data illustrating each of the first order concepts in Fig. 2.

Nonetheless, the data structure shows a static picture of what de-facto is a dynamic phenomenon, as it does not capture the dynamic relationships among the $2^{\text {nd }}$ order themes and aggregate dimensions (Gioia et al., 2013). As such, we subsequently drew on systems thinking, representing our findings in the form of a Causal Loop Diagram (CLD: Sterman, 2000 ), to arrive at a dynamic explanation of how academics evolved in their boundary spanning approach and ability over time (Fig. 3). CLDs originated in the system dynamics literature (Sterman, 2000) and have become common in management and organization studies (e.g., Dattée et al., 2018; Perlow et al., 2002; Van Oorschot et al., 2013; Walrave et al., 2011), to capture and explain feedback driven systems involving dynamic behavior over time (Lin et al., 2006; Stacey, 1993). We observed significant behavioral changes about halfway into the project. As such, we used temporal bracketing (Van de Ven \& Poole, $1995)$ to identify two main episodes to further characterize the sequence of events and related themes. These episodes ( 1 and 2 ) do not coincide with the formal project's phases; rather, they relate to the two feedback loops in our CLD (i.e., loops B1 and B2, in Fig. 3) and mark a major change in the academics' behavior and communication patterns over time. This insight forms the basis of our findings, detailed in the next section.

\footnotetext{
${ }^{1}$ We argue for the effectiveness of this approach when investigating academics with limited academic engagement experience, as there are ample learning opportunities readily observable to the researcher. This approach would need to be reconsidered when investigating academics with substantial academic engagement experience.
} 


\section{$1^{\text {st }}$ order concepts \\ $2^{\text {nd }}$ order themes \\ Aggregate \\ dimensions}

- University vs. industry knowledge level
- Lack of industry knowledge

- Outreach activities

- Knowledge sharing activities

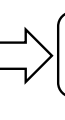

Knowledge gap with industry

- Industry response to outreach

- Industry interest in technology

- Industry adoption and application of technology

- Experience with industry interaction

- Experience with commercialization

- Experience with outreach activities

- Sharing of technical details and specifications

- Sharing academic presentations, journal articles and documents

- Technology push perspective

- Tailoring information to industry context

- Customizing communication

- Awareness of reciprocal understanding
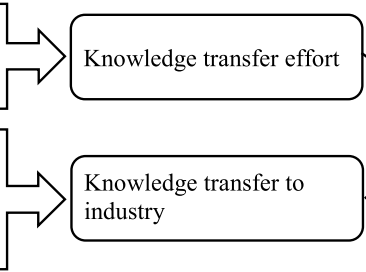

Closing the

knowledge gap

- Differences in understanding and
expectations
- Difference in communication and language

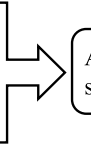

Knowledge transfer to industry

- Taking the perspective of industry

- Consider industry's point-of-view on technology

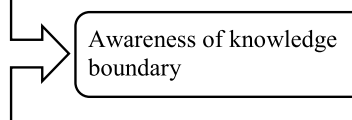

Semantic/pragmatic spanning approach

- Envisioning industry applications

- Understanding industry operations and

decision-making processes

- Commercial insights

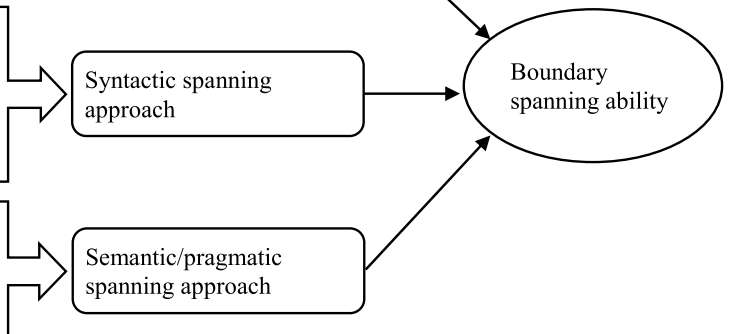

Fig. 2 Data structure

\section{Findings}

We present our findings through a detailed construction of the CLD representing academics' boundary spanning ability development based on our data. The final model is presented in Fig. 3, which we will narrate and ground in our data in the remainder of this section. In this respect, Table 2 provides supplemental empirical evidence for each of the key concepts in our CLD. We start with the context and aim of the NewTech project, modelling the academic engagement initiative in the 'Academic engagement loop'. We then develop the 'Boundary spanning ability development loop' to capture 


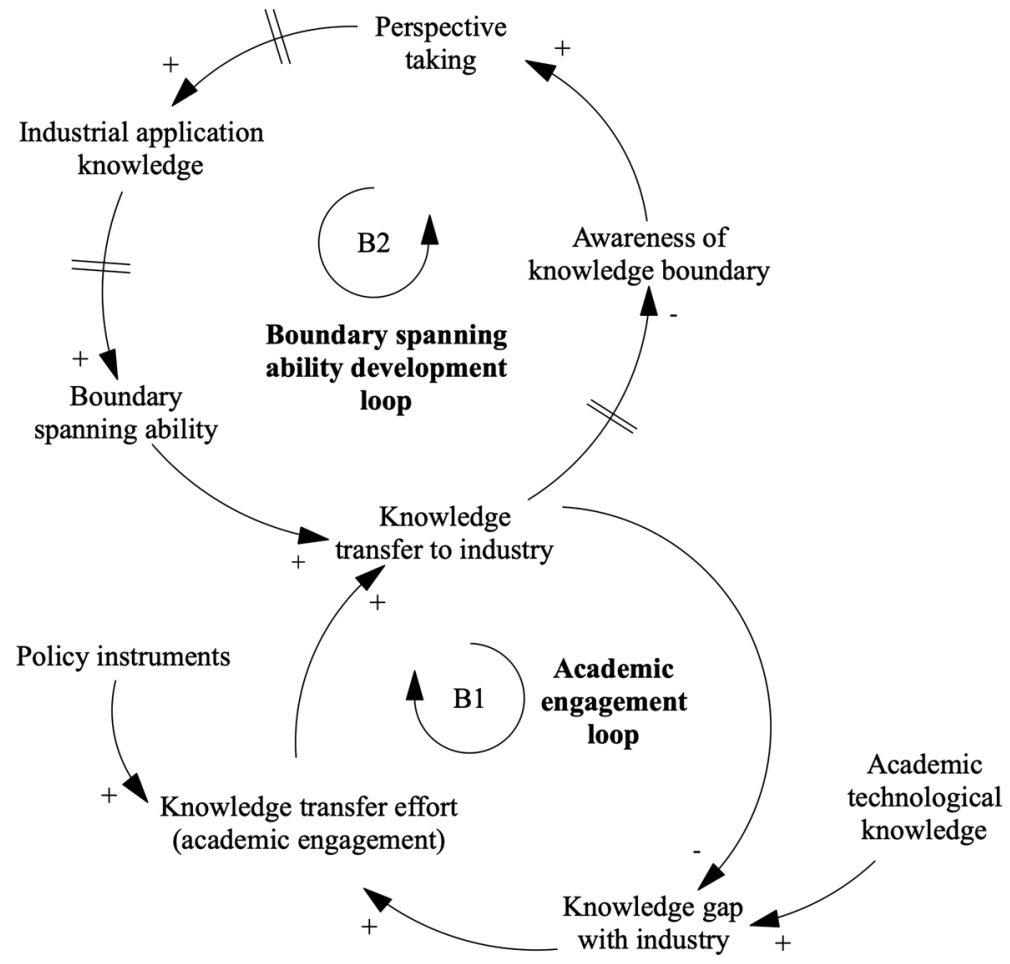

Fig. 3 Causal loop diagram of the academic engagement and development of boundary spanning ability during technological knowledge transfer activities. The ' $\mathrm{B}$ ' labels denote the balancing nature of the feedback loop. The '+' and '-', on the arrows, denote the polarity of the causal links, the signs denote substantial delays (see Sterman, 2000)

the process by which academic engagement builds boundary spanning ability. The two loops within Fig. 3 each represent a temporal bracket, or episode. During the first episode, feedback loop B1 is dominant, capturing the major behavioral dynamics within the project. During the second episode, however, loop dominance shifts to feedback loop B2. ${ }^{2}$

\subsection{Episode 1: The 'Academic engagement loop' (Loop B1)}

The central flow of the NewTech project revolves around knowledge transfer and academic engagement. At a high level, the sequence of events we observed during episode

\footnotetext{
${ }^{2}$ The analysis and modelling using CLDs represents a-to the best of our knowledge-novel technique in The Journal of Technology Transfer. We hope to familiarize JTT's readership with the potential of using CLD-based research to model and better understand the complex and dynamic behavior underlying technology transfer processes and outcomes.
} 


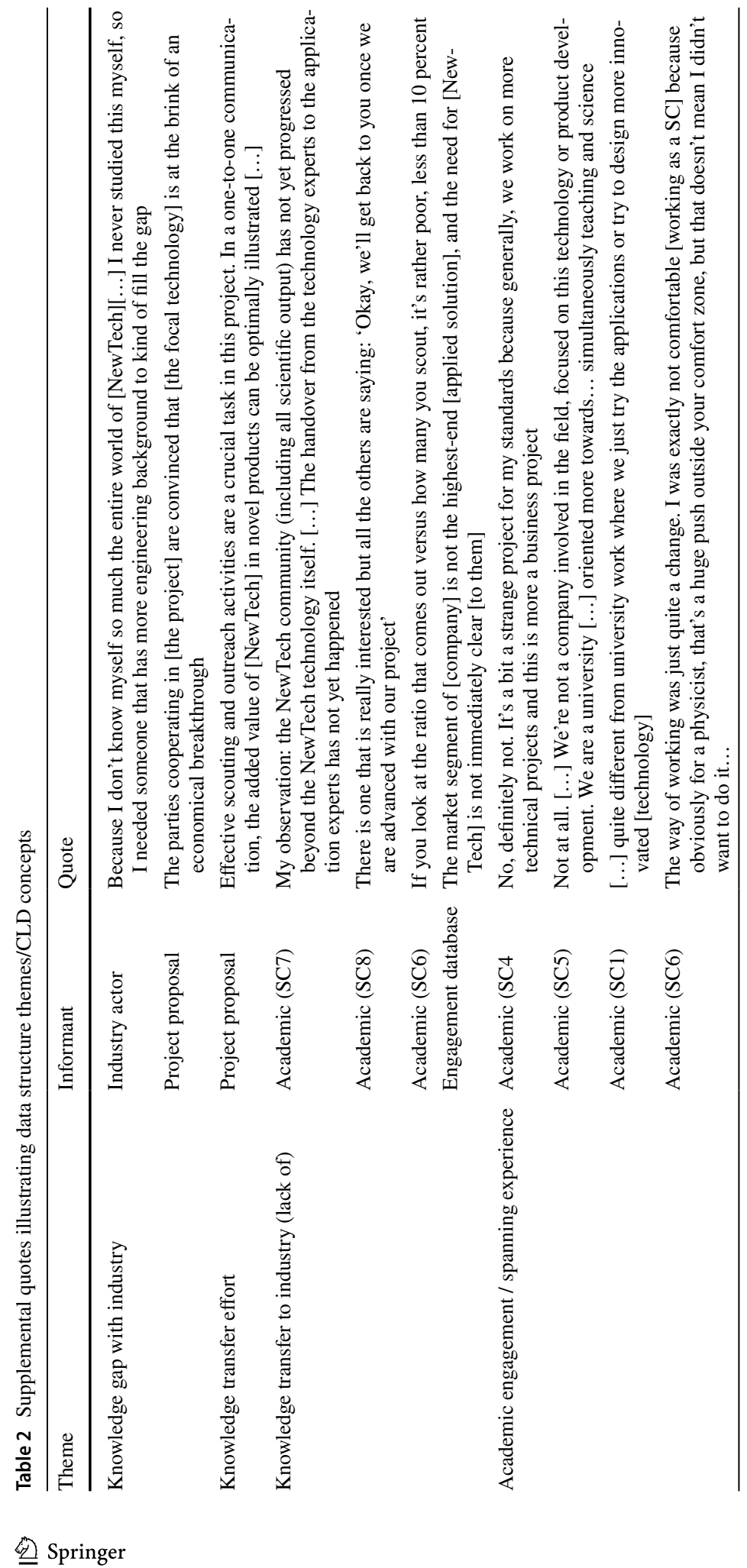




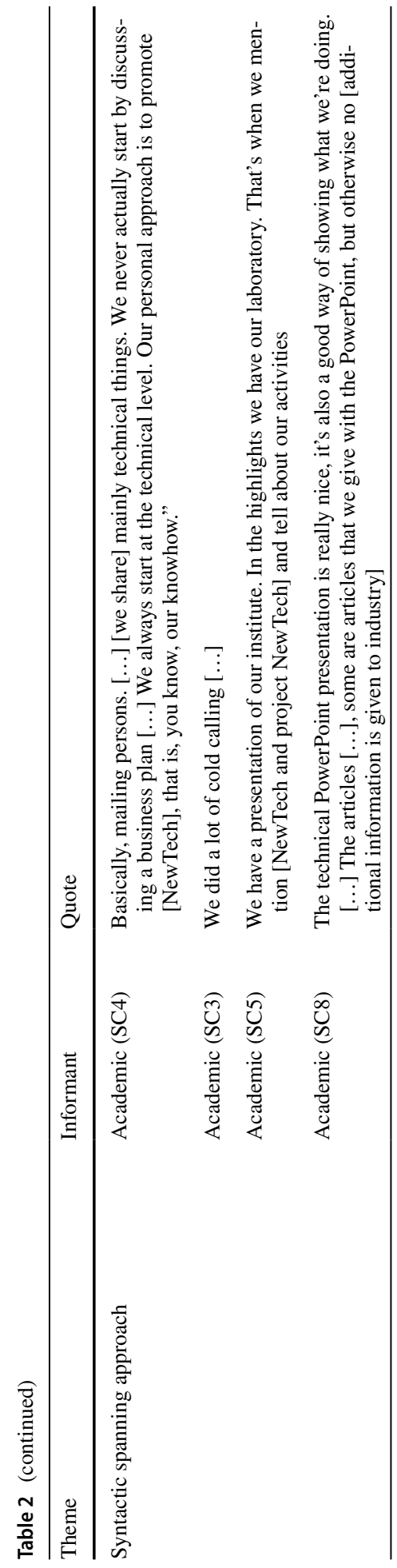




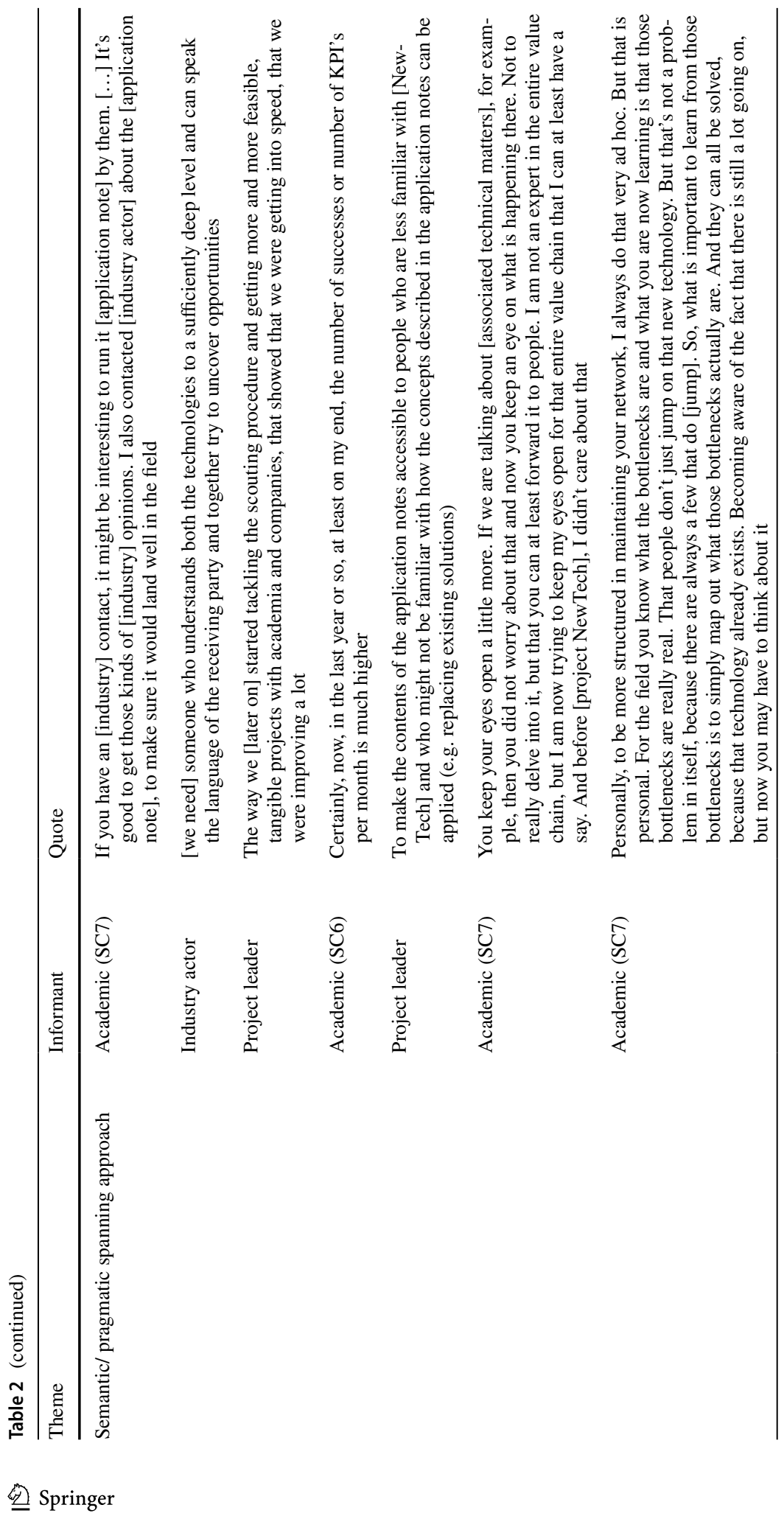




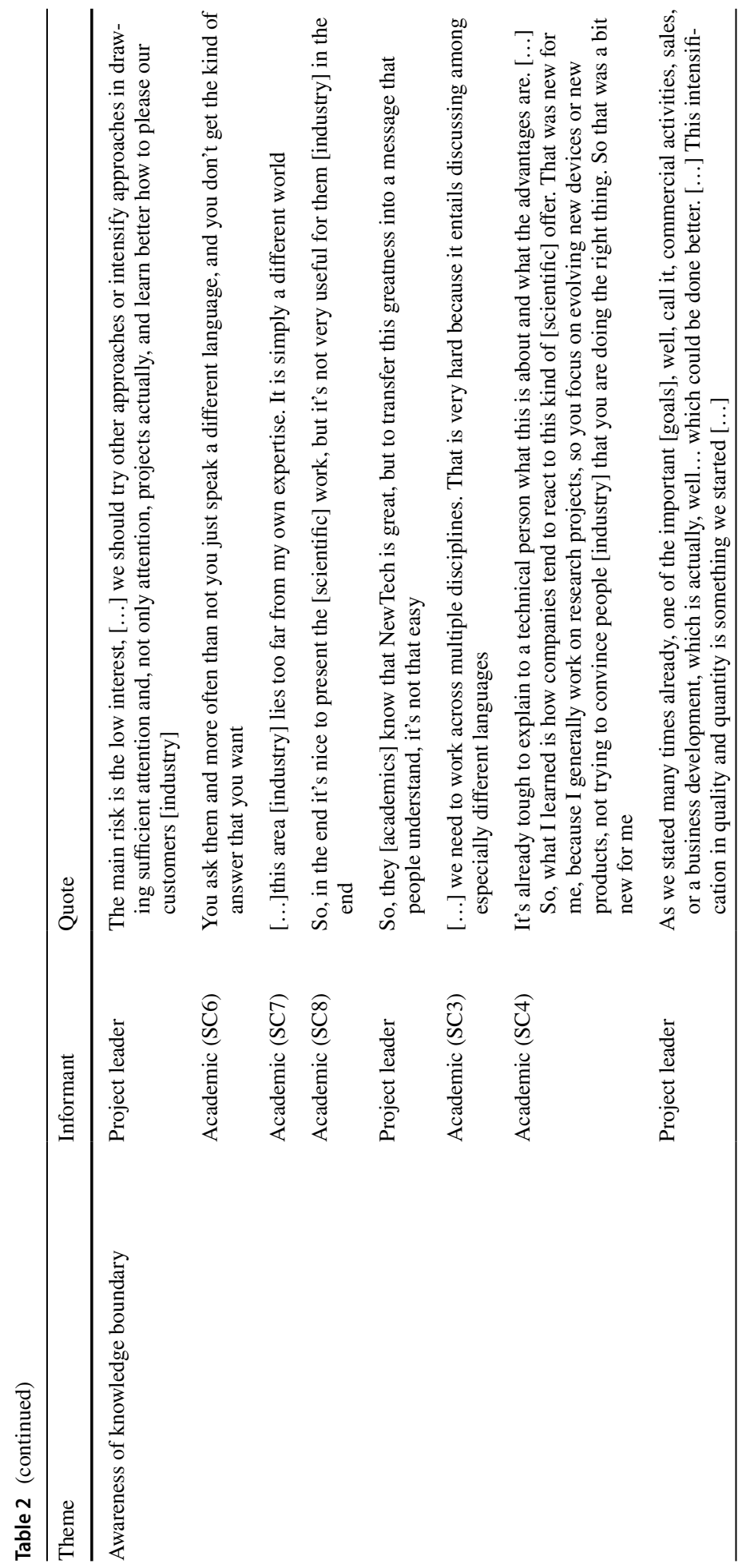




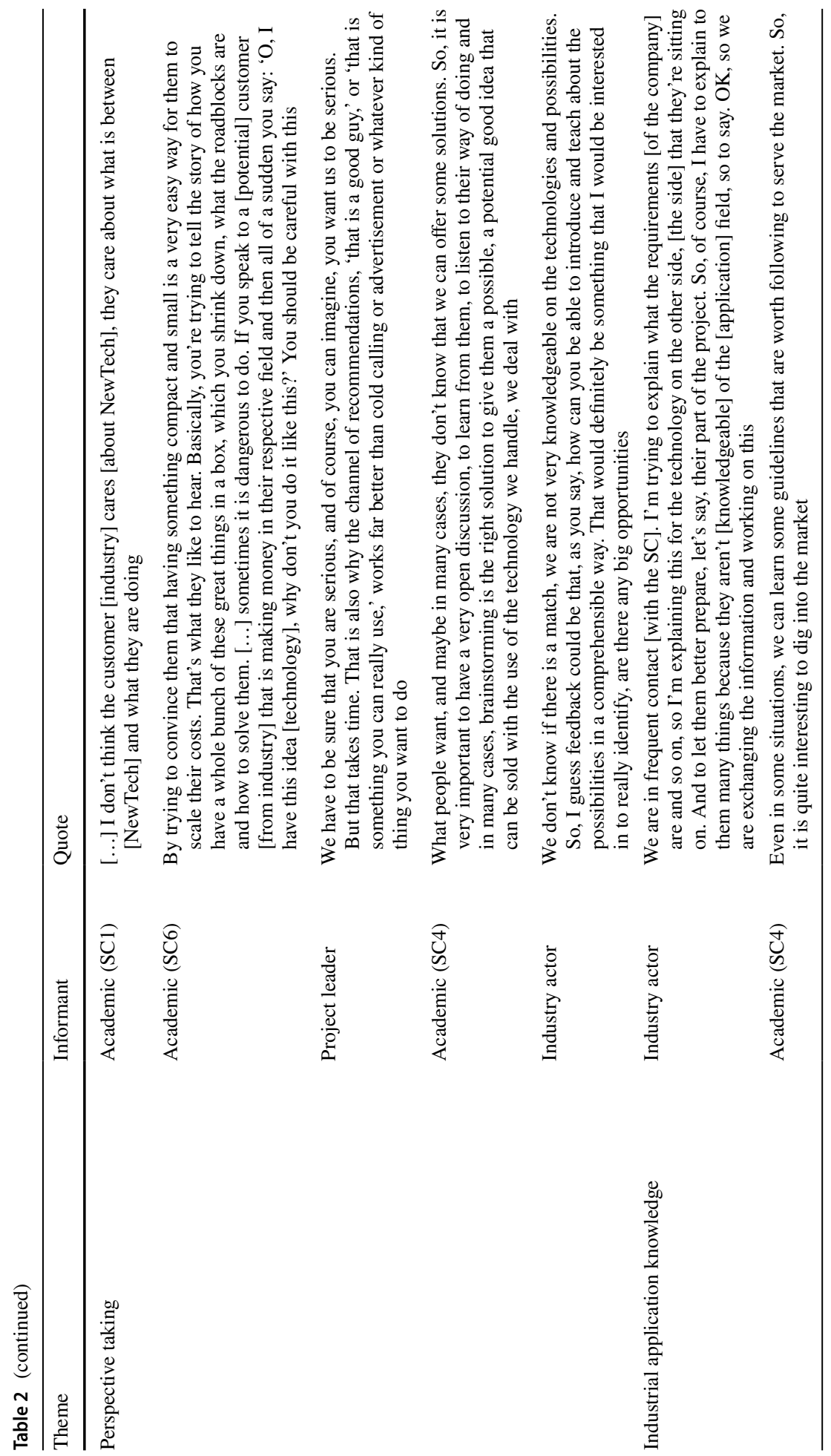


1 is largely consistent with expectations we identified in our review of prior literature above. We capture the events in the balancing feedback loop B1, termed 'Academic engagement loop' in Fig. 3 and narrate our observations with relevant data.

\subsubsection{Knowledge gap with industry}

Academics have researched NewTech technology for many years. While NewTech is technologically superior to many existing solutions, industry knowledge and adoption of NewTech lags. The NewTech grant proposal was therefore developed by a consortium of academics from nine universities in response to the 'Knowledge gap with industry'. Quite simply, the academics observed a significant amount of specialist 'Academic technological knowledge', but little 'Industry technological knowledge', regarding NewTech. This 'Knowledge gap with industry' severely limited commercial adoption and application of NewTech as industry did not access or assess NewTech for their commercial projects. An Academic of SC4 explains:

I think it's really necessary to have [project NewTech] because otherwise none of the companies [...] could access this technology because it's too specialist, too expensive at the beginning, you know the very first step into the technology could be really impossible without the support of the SC [Support Center within the university]. In general companies don't have any knowledge about [focal technology].

\subsubsection{Knowledge transfer effort (academic engagement)}

The NewTech 'Knowledge transfer effort' was formalized by the consortium of academics in the grant proposal. In response to the 'Knowledge gap with industry', and enabled by a European grant denoted by the exogenous variable 'Policy instruments' in Fig. 3, each of the nine universities established a Support Center (SC) tasked with transferring knowledge to industry, as described in this excerpt from the project proposal:

By establishing expert SCs distributed over Europe, we will bring [NewTech] to the doorstep of many [...], thus enabling Europe to take a maximum benefit of these technologies. We expect that this distributed model, in which the SCs will actively scout and support potential beneficiaries in their own region, shall increase the effectiveness [...]

At the start of the project, however, academics possessed little experience with academic engagement or transferring knowledge to industry, as the academic of SC2 states:

"No experience. I hadn't taken part in any commercialization activity before."

This low level of experience with technology transfer is not surprising. While academics possess in-depth knowledge in their respective fields, individual researchers are typically less knowledgeable in matters associated with technology transfer, or, more generally, academic engagement (see, e.g., MacGregor et al., 2010; Miller et al., 2018). Specific to this project, the academics involved did not identify knowledge transfer activities to industry as part of their everyday tasks, unlike activities such as teaching and research. 


\subsubsection{Knowledge transfer to industry}

As the project started, the academics, with little deliberation, began with a direct, syntactic approach to industry - unaware of the more complex knowledge boundary they needed to bridge. Having little or no experience, most academics began outreach by contacting existing relations to inform them about the project and "cold" calling/emailing (previously unknown) companies they felt might be interested in NewTech. Once the academics established an industry contact, they proceeded to share straightforward technical research findings (e.g., technology specifications obtained in lab settings) and academic presentations (e.g., academic conference presentations) with the industry actors (companies) to attempt knowledge transfer of NewTech. Initial engagement efforts (i.e., merely communicating NewTech's specifications) yielded little interest, reflected in this quote from an industry actor:

[SC7] contacted us in, I can say in September 2016. Introducing the project [...]. So, I evaluated that. I didn't really see an immediate overlap there [in NewTech] being potentially relevant for our business. It is a completely different technology platform... There were a couple of follow up emails [by SC7] in 2017, basically again with the same result. I replied that we didn't have any feedback. We don't immediately see the application possibilities [of NewTech]. But if you - [as SC] through your expertise [...] and knowing what we do - if you think that there are specific areas that could be of interest for us, then provide those suggestions and then we can consider that further.

The academic of SC4 reflects on their efforts:

"Generally, they [industry] are interested or they are just being kind, I don't know. But we talk and we share some information on the technical side and then it fades out... No one calls back. Or they [industry] say: 'Okay, we will see', and that's it.

During a presentation in a project review meeting around month 18 (approximately a year after the industry actor quote above), a project leader clearly recognizes the failure of the initial syntactic approach to industry in transferring NewTech technology:

There is the assumption that OK we presented ourselves, our technology is great.

So, the people will come to us. But it never happens.

At that point, one and a half years into the project, only 2 of the 111 logged outreach activities in the online engagement database had resulted in the initiation of developing an actual prototype. This represented a significant shortfall for that key performance indicator (KPI) of the project. The original proposal set a goal of 200 outreach activities and 100 prototypes at project completion, only another 18 months away. Without effective knowledge transfer, industry was not able to increase their technological knowledge on NewTech. The academics, despite in-depth knowledge in their fields and interaction with industry actors, failed to close the knowledge gap. One of the project leaders describes the impact of NewTech's lack of progress in 'Knowledge transfer to industry' in an email:

Now that the project has been operational for some time, we think it is a good time to reflect on the current progress. [...] As a first conclusion, it appears that with the current pace and progress, we will not make the projects KPI's - which, as you can imagine, is problematic. [...] If we don't live up to the standards we 
promised in the project proposal, we run a serious risk of being cut in our budget or even the project could be terminated completely! [...] Based on the information entered in [the online engagement database], there is currently very little effective [engagement] activity (leading to actual work with companies/institutes). [...] Furthermore, we also have the impression that in the last 1,5 years you all have been sending out information, in workshops and meetings, hoping for response from 'the market'. However, the response has been very low.

\subsection{Episode 2: The 'Boundary spanning ability development loop' (Loop B2)}

About one and a half years into the project, we observed a gradual tipping point or behavioral shift, as some academics started to realize their inability to effectively transfer knowledge to industry. We capture this realization and its further implications with the balancing feedback loop we term the 'Boundary spanning ability development loop' (loop B2, in Fig. 3). We narrate our observations and present data relevant to loop B2 here.

\subsubsection{Awareness of knowledge boundary}

Our data provide us two observations about 'Awareness of knowledge boundary'. The first is that it requires a significant amount of time. In the case of NewTech, we did not witness this awareness emerge until about 18 months into the project. The second is that it requires critical mass. It was not until both academics and industry actors together shared the awareness of the knowledge boundary that activity began to shift into the 'Boundary spanning ability development loop'. Below is an example quote from the academic from SC1 sharing his realization:

The thing that strikes me, actually is that when you talk about a new [industry] lead, we always talk about the technology and I don't think they [industry] can.

The corresponding quote from one of the industry actors at the same time describes the academics' inability to span the knowledge boundary:

[...] after really a lot of discussions, we really made more of our expectations realistic [...] so I think that it was, as usual, not the technical matters but the communication level was a bit, not problematic, but made a lot of differences between us at the beginning.

As the academics started to realize their approach for crossing the knowledge boundary between science and industry was ineffective, they became more aware of the knowledge boundary between academia and industry and impedes effective knowledge flow. This realization is responsible for a collective shift of the project effort to figuring out how to solve it.

\subsubsection{Perspective taking}

Aware of the knowledge boundary between academia and industry based on how industry perceived their activities, the academics started to better understand why their knowledge transfer was ineffective. As the academics began to make sense of the knowledge boundary, they started to engage in what we identified as 'Perspective taking'-actively considering 
the industry perspective and how industry actors may perceive NewTech. The academic of SC6 reflects:

If you show them your technology, you show them all the great numbers of speed and all the parameters. At some point you are going to get lots of questions. They swallowed all [...], that's fine, but all of a sudden, the specific point doesn't seem that important. Then you see what is important to them [industry]. They [industry] might not believe it's going to work out for them. Also, on the psychological side, we are making it tasty for them, in a way that they won't get scared of all the complexity of all the technology. We give them a solution they want to believe in. That's pretty important.

Furthermore, reciprocal knowledge exchange (between the academics and industry) also requires trust, which takes time and effort. A project leader explains:

One of the things I remember, is that one of the [companies] said is that we are, in such a project, working together in an exploratory manner. So, what is needed [...] is that we build confidence. And confidence [...] is not coming overnight.

A telling quote on the matter of perspective taking came from the academic of SC7 closer to the project conclusion, reflecting on changes over the course of the project. The impact of perspective taking is immediately evident both in the way the academic thinks about industry actors on the other side of the knowledge boundary and the activities required to span that boundary:

Yes, you have to take the perspective of the company. [...] What you often see with scientists is that they want to sell their own ideas. What you have to do, and we already did that a bit, is that you may be able to use those ideas during an interaction, but in fact you have to come up with something they want. And that's good if you can guide something like that, those ideas, then you have a win-win situation.

The various academics involved in the project employed different perspective taking strategies (see Table 2), likely reflecting their own individual communication styles. The academic of SC1 considered perspective taking a way to make industry care about his technology. The academic of SC4 used a joint brainstorming approach with industry actors to animate his own form of perspective taking. And more of a listener, the academic of SC6 carefully determined what industry 'needed to hear' in order to get their attention. These various approaches to perspective taking indicate that there is no one correct implementation, but that perspective taking can assume a variety of individually enacted approaches.

\subsubsection{Industrial application knowledge}

As a result of perspective taking, the academics gradually gained insight in 'Industrial application knowledge'. In other words, they increasingly developed a better understanding of the industry and market needs associated with NewTech. In the following quote, an academic of SC3 reflects on how he now better understands main industry decision criteria or tradeoffs when considering the adoption of a new technology such as NewTech:

Most of them [industry actors] have different degrees or different reasons why each one is interested either technically, scientifically or from a commercial perspective. Technically and scientifically, most people [industry actors] are always interested. I 
think it's an appealing technology and through the project [NewTech] they get to understand what the benefits of the technology are. But in terms of commitment or committing their own funds or getting into a [joint] project [with academia], that is very particular to each of them and that depends on many, many things. For instance, for companies, it depends on company strategy because companies, of course, do not get fully funded by some agencies. So, either they are really into it or they don't do it. So, a main reason [for them] to step back is whether they believe this [NewTech] is going to be something [that will be incorporated] in their future products or not. If that is compatible, of course, they want to invest in this [NewTech].

\subsubsection{Boundary spanning ability}

Over time, by engaging in 'Perspective taking' and gradually gaining 'Industrial application knowledge', the academics developed their 'Boundary spanning ability'. They advanced into approaches Carlile (2004) would term knowledge 'translation' and 'transformation' as they learned to communicate from the perspective of industry-an essential feature of boundary spanning ability when dealing with uncertain new technologies. In one clear example of this transition, some academics started to create dedicated boundary objects, in the form of 'application notes' to inform industry of the possible applications of the technology in a less scientific manner. Such activities indicate moving from basic syntactic boundary spanning toward semantic approaches that attempt to adopt the terminology of recipient. The academic of SC7 explains how he and the other academics evolved in their approach towards developing effective boundary objects (application notes) by engaging with industry:

The first [NewTech promotional] document was one massive technology push, without any regard for the market [industry]. [...] There shouldn't be too much academic push, because that won't work. And that's exactly the type of reaction we get sometimes. In response to some of the [first] application notes, for example, people [industry actors] have come up to us, telling us: 'What the $\mathrm{h} * 11$ did your write there, that has absolutely nothing to do with what industry wants'. So that's an ongoing point of attention for us.

Both the academics and the project leaders highlight the role of application note prototyping and reciprocal knowledge exchange with industry in developing effective boundary objects. Through iterations and feedback, the academics began to create dedicated application notes to serve as effective boundary objects in engaging with industry. The academic of SC6 proudly reflects on the positive impact that the application notes had on the ability to engage with industry:

Yes, because if you have a piece of paper in your hand immediately you look more serious because that's actually data, there are numbers and pictures, examples, contact persons and stories. Three of the application notes, or even more, were on [specific application of NewTech], so if you want to engage in a discussion with somebody who works in that field it's much more useful to have this sort of material even though it's not exactly what they do but maybe related. Rather to have this in your hands than some generic [NewTech] great sort of promotion material.

As the academics became increasingly aware of the nature of the knowledge boundary and how to respond to it, they were able to start translating and transforming their 
academic knowledge in ways that would interface well with industry, facilitating 'Knowledge transfer'. Over time, the academics learned-albeit with substantial delay - to match their boundary spanning approach with the knowledge boundary faced. Those academics who entered the boundary spanning ability development process began to experience changes in their own ability and effectiveness in the context of the project. By the final months of the project, the academics' knowledge transfer effectiveness improved significantly. The academic of SC3 reflects:

I think I have learned a lot in terms of preparing events, getting things together, planning meetings and making or creating situations in which people get to talk to each other in a rather easy way. To create a value of this project is how to create the ambience to get people together to talk and ascertain a future collaboration. [...] Perhaps what we've been able to detect faster than before is whether there is a genuine interest in [NewTech] and a commitment or not. At the very beginning, everybody appears to be very enthusiastic and committed to what you're telling them. [...] Now you can predict it better than at the very beginning. At the very beginning, every [industry actor] seems to be a lead that is going to be converted into a [NewTech] user but at this moment we know which ones are easy to get into a [NewTech] user or others that are far away and maybe are just curious about the technology.

However, toward the end of the project, the academics and project leaders also realized how they underestimated the boundary spanning challenges they faced during the project as well as the time and effort involved to (develop the necessary boundary spanning ability to) overcome these challenges. The academic of SC7 reflects:

"Now and then I have the idea that we believed a little too much in ourselves, that it would be easy. [...] I have the idea that people thought about it too lightly, well, I'm pretty sure that people thought about it too lightly. [...] I can't bridge these two distinct fields [academia and industry] in the little time I normally spend on [project NewTech]. It's a real challenge. [...] Networking, sending an email again, figuring something out, searching through a few papers to answer someone's question. So, it takes a lot of time...

The academic of SC1 adds:

"So, we thought it would be easier, just to go to a few companies and say [NewTech] is great."

Despite the challenges, the project and leaders and academics running the SC's completed the project with positive outcomes. The online engagement database lists 237 scouting activities (target was 200) and 50 prototypes (target was 100). This comprises the balancing 'Boundary spanning ability development loop' (Loop B2, in Fig. 3) where we observe how academics learn to become boundary spanners. This challenging process requires academics to realize the knowledge boundary and be able to actively engage in perspective taking, which in turn improves their industrial application knowledge and ultimately results in the development of academic's boundary spanning ability - the heart of effective academic engagement and knowledge transfer to industry. The academic of SC6 reflects on how development of his boundary spanning ability through participating in the NewTech project can be applied to new situations:

It's some sort of mind-set of walking up to people who work in completely different areas and run completely different business, trying to understand what they actually 
do and if we can do something together, which is super-valuable in all sorts of things. For instance, now I have an invitation to speak at a conference on [NewTech]. I'm sure I will meet many different people from different backgrounds, quantum people, whatever, where exactly this will come into play. Also, I think the fact I got invited comes down to [...], of course, not just because of project [NewTech] but because of the project I became more versatile communicating and networking with people, and that's why it came up in the first place.

\section{Discussion, future research and limitations}

This study set out to investigate how academics learn to span boundaries during academic engagement. Drawing on a longitudinal, in-depth case study of a large European publicly funded project directed to transfer university developed technology 'NewTech', we find that academics evolve in their knowledge transfer approach over time-reflective of boundary spanning ability. Our findings show how structured or systematic academic engagement may lead academics to become aware of the knowledge boundary that exists between science and industry. Awareness of this knowledge boundary is a first and important step toward developing boundary spanning ability. In turn, engaging in perspective taking is crucial to gaining the necessary industrial application knowledge that allows academics to successfully translate and transform academic knowledge to span the knowledge boundary with industry. As such, perspective taking offers a mechanism to explain the development of boundary spanning ability and hence effective academic technology transfer or commercialization. Our findings offer important implications for future research which we organize according to topic.

\subsection{Academic engagement}

Prior work investigates antecedents of academic engagement, such as individual characteristics, capabilities, and firm-related variables (e.g., Filippetti \& Savona, 2017). But few scholars stop to consider the potentially endogenous nature of the relationship between those antecedents and outcomes relating to successful technology transfer or engagement with industry. Our findings show that academic engagement ability is, at least partially, shaped by the engagement activity itself. As such, our findings shed important new light on existing work on academic engagement, including limitations that may arise from only considering one-way relationships between antecedents and outcomes. This implies scholars might start looking beyond (fixed) antecedents and assumed linear effects to explain academic engagement (outcomes), and consider more complex matters such as the dynamic learning behavior described in this study. In addition to applying CLDs, system dynamics modeling may prove a particularly valuable research method (see Sterman, 2000; Walrave et al., 2011). Furthermore, we expose ways development of boundary spanning abilities in the context of academic engagement might be traced. The emergence of academics creating industry 'application notes' (loop B2, Fig. 3) as part of their engagement efforts offers a concrete artefact of boundary spanning ability development. And while different contexts may generate different artefacts, 'application notes' offer a clear example of how academics evolved in their boundary spanning ability by creating custom boundary objects.

Focusing on future research questions, we are quick to acknowledge we show only one learning path for the development of ability in academic engagement. Do other paths 
exist? Is there co-learning (Rossi et al., 2017) between transferrer and recipient, necessitating studies analyzing both actors simultaneously (Ankrah et al., 2013)? And what is the impact of facilitating entities such as technology transfer offices (Cesaroni \& Piccaluga, 2016) in mediating variables like learning? To address these questions and more, our results invite further longitudinal study of academic engagement. Prior work acknowledges that academic engagement initiatives span lengthy timeframes (Jonsson et al., 2015), and we observed significant time delay simply due to learning processes. Are there generalizable phases in the process? Are the phases path dependent (Krücken, 2003)? And what are the causal links and feedback processes in the process (CLD modelling may be particularly useful for future research efforts)?

\subsection{Perspective taking}

A novel and central insight from our data is the importance of perspective taking as an engine for effective boundary spanning in the academic engagement process. Perspectivetaking concerns "the active cognitive process of imagining the world from another's vantage point or imagining oneself in another's shoes to understand their visual viewpoint, thoughts, motivations, intentions, and/or emotions" (Ku et al., 2015: 79). Research on perspective taking originated in the psychology discipline, investigating human interactions and the way people understand what other people are thinking (Galinsky et al., 2005; Stueber, 2008). As a construct, perspective taking combines both cognitive processes and individual social interactions (Gehlbach, 2004; Gillespie \& Richardson, 2011; Martin et al., 2008). In light of findings regarding the generally positive effect of perspective taking on enhancing interactions and relationships of diverse actors (Ku et al., 2015), application of perspective taking to situations requiring boundary spanning makes intuitive sense. Our work coheres with related findings that perspective taking can act as a mechanism underlying another phenomenon (Galinsky et al., 2005). Hustad (2007), for instance, draws a positive connection between the use of perspective taking and building new social networks. Hoever et al. (2012) demonstrate the importance of perspective taking as a mechanism that enables team creativity by encouraging diversity. Furthermore, Litchfield and Gentry (2010) describe perspective taking as a mechanism that underlies organizational capability by enabling the creation of social bonds and social coordination. Our work adds to these with the finding that perspective taking provides a mechanism underlying the development of boundary spanning ability. Future work may seek to further uncover how perspective taking influences academic engagement outcomes.

As we argue for further research investigating perspective taking, we are careful to point out that it may be enabled by a sub-mechanism of perspective making (Boland \& Tenkasi, 1995), whereby individuals internalize the observations and experiences gained from taking the perspective of another. And while our data do not expose such a nuanced effect, we recognize it may be at work beneath what we observe, suggesting another interesting path for future investigation.

\subsection{Academic careers}

The literature on academic careers clearly establishes the tension between research and teaching (Rice et al., 2000). Our findings allude to the added pressure of academic engagement, suggesting an important area of focus for scholars studying the balance of multiple responsibilities in academic careers (Muscio et al., 2017). We anticipate a growing need 
for academics to culture an exotic form of ambidexterity (Sengupta \& Ray, 2017) as they simultaneously teach, conduct research, engage with industry, and learn how to do it in the process-which, as our results show, is challenging. Placing such tall orders on academic researchers will demand focused and thoughtful intervention by their institutions to set aside the time necessary to be successful in academic engagement and accelerate the development of enabling skills such as boundary spanning abilities. This represents both an important practical task as well as area of future research investigating the efficacy of different interventions on academic engagement outcomes.

\subsection{The relationship between academic research and engagement}

An implication of our work is the addition of contingency to prior conclusions in the literature. Notably, Perkmann et al. (2013) argue that academic engagement is closely aligned with traditional research activities. Our findings suggest this not to be the case for the relatively inexperienced academics engaged in project NewTech. Our informants underestimated both the complexity of the knowledge boundary and the effort required (developing the necessary ability) to span it. We observe that as the academics needed to divide time between research, teaching, and academic engagement, tensions started to arise. Here, we call for more research on the relationship between multiple responsibilities to better understand when the set of tasks generates virtuous feedback versus conflict, tension and reduced academic effectiveness.

\subsection{Boundary spanning}

Boundary spanning encompasses a significant discussion in the literature (e.g., Carlile, 2002, 2004). While much of our interaction with that discussion benefits us in setting up and executing our investigation, but we have a contribution to offer in return. The finding that perspective taking provides a mechanism for how boundary spanning ability is accumulated during academic technology transfer offers important implications for boundary spanning theory in general. Is perspective taking always at work when individuals learn to span knowledge boundaries, or is only relevant in more complex, high novelty situations (Carlile, 2002)? What other mechanisms enable the accumulation of boundary spanning ability? Does boundary spanning ability generated in a specific situation such as academic engagement transfer to different situations or challenges, particularly when the conceptual nature of the boundary may differ? Furthermore, by conceptualizing academic engagement as a process of boundary spanning, we show how some academics evolved in their approach over time. And while our study demonstrates the usefulness of using boundary spanning theory as a lens to capture the dynamics of academic engagement, more research is needed to explore the role of factors such as willingness, incentives, ability and motivation which may facilitate the process.

\subsection{Policy implications}

Our findings also offer important implications for policy makers. Notably, we demonstrate that academics' development of their ability to effectively transfer knowledge is subject to substantial delay. This implies the typical lead time of many EU funded projects to stimulate academic engagement or (university) technology commercialization, about two to four 
years, might be problematic. Academics may require significantly more time to (a) realize the existence/type of the knowledge boundary, (b) and engage in perspective taking, (c) to gain industrial application knowledge and thereby develop their boundary spanning ability, as indicated in our data. As such, policy makers might take note of our findings to develop policy directed to stimulate perspective taking among academics in preparation to engage in boundary spanning activities. Such initiatives might offer methods, tools, training activities or specific support initiatives which might help accelerate the loop we describe in B2 (Fig. 3).

\subsection{Limitations}

We appreciate that there is no such thing as a perfect study, and ours is no exception. As much as we enjoy the benefits of the rich data we collected over a three-plus year period observing the NewTech project, the limitations of our data, analysis, method and results are many, and as always point to additional future research possibilities. We highlight three such issues here, recognizing the incompleteness of the list. First, we draw inference from a single project, raising questions about how our results might generalize, particularly to projects with very different knowledge boundary characteristics (Carlile, 2002). Second, we use our longitudinal data to model casual relationships in our CLD. While ours represents an illustrative first step, establishing true causality is always a challenge and needs validation in additional settings, with additional data and alternative methods. A possibility for future research following our work is to formalize the CLD model into a system dynamics simulation model (Sterman, 2000). By doing so, the dynamics that follow from the different feedback loops can be studied in more detail. Third, to develop a parsimonious model, we do not account for (individual) exogeneities, such as financial incentives, career incentives, or team/group incentives. Prior research shows these variables exert impact on outcomes in similar situations and merit consideration in future investigations.

\section{Conclusion}

Stepping back from NewTech and our study, we attempt to gain some perspective. The pace of academic research and new technology adoption are only increasing with the passing of time. The pressures of population growth, climate change and economic inclusion are demanding greater and greater innovation. Against this backdrop, the general topic of how to improve the flow of (technological) knowledge from top minds conducting research to enable innovation becomes increasingly important. Our study represents only one aspect of this global mega-trend but contributes in some small way. As much as it may better enable those responsible for critical boundary spanning roles, we hope it more generally raises awareness of the issue and encourages further work in the field.

Open Access This article is licensed under a Creative Commons Attribution 4.0 International License, which permits use, sharing, adaptation, distribution and reproduction in any medium or format, as long as you give appropriate credit to the original author(s) and the source, provide a link to the Creative Commons licence, and indicate if changes were made. The images or other third party material in this article are included in the article's Creative Commons licence, unless indicated otherwise in a credit line to the material. If material is not included in the article's Creative Commons licence and your intended use is not permitted by statutory regulation or exceeds the permitted use, you will need to obtain permission directly from the copyright holder. To view a copy of this licence, visit http://creativecommons.org/licenses/by/4.0/. 


\section{References}

Aguinis, H., \& Solarino, A. M. (2019). Transparency and replicability in qualitative research: The case of interviews with elite informants. Strategic Management Journal, 40(8), 1291-1315.

Aldrich, H., \& Herker, D. (1977). Boundary spanning roles and organization structure. Academy of Management Review, 2(2), 217-230.

Ankrah, S. N., Burgess, T. F., Grimshaw, P., \& Shaw, N. E. (2013). Asking both university and industry actors about their engagement in knowledge transfer: What single-group studies of motives omit. Technovation, 33(2-3), 50-65.

Beechler, S., Søndergaard, M., Miller, E. L., \& Bird, A. (2004). Boundary spanning. In H. W. Lane, M. L. Maznevski, M. E. Mendenhall, \& J. McNett (Eds.), The Blackwell handbook of global management: A guide to managing complexity (pp. 121-133). Blackwell Publishing.

Bekkers, R., \& Freitas, I. M. B. (2008). Analysing knowledge transfer channels between universities and industry: To what degree do sectors also matter? Research Policy, 37(10), 1837-1853.

Bercovitz, J., \& Feldman, M. (2007). Academic entrepreneurs and technology transfer: Who participates and why? In F. Malerba \& S. Brusoni (Eds.), Perspectives on innovation (pp. 381-398). Cambridge University Press.

Boardman, P. C., \& Ponomariov, B. L. (2009). University researchers working with private companies. Technovation, 29(2), 142-153.

Boland, J. R., \& Tenkasi, R. V. (1995). Perspective making and perspective taking in communities of knowing. Organization Science, 6(4), 350-372.

Bonaccorsi, A., \& Piccaluga, A. (1994). A theoretical framework for the evaluation of university-industry relationships. R\&D Management, 24(3), 229-247.

Booz, R. J., \& Lewis, L. K. (1997). Facilitating technology transfer among organizations: An applied communication strategy concept for organizational boundary spanners. The Journal of Technology Transfer, 22(1), 35-46.

Brown, J. S., \& Duguid, P. (1998). Organizing knowledge. California Management Review, 40(3), 90-111.

Calcagnini, G., \& Favaretto, I. (2016). Models of university technology transfer: Analyses and policies. The Journal of Technology Transfer, 41(4), 655-660.

Carlile, P. R. (2002). A pragmatic view of knowledge and boundaries: Boundary objects in new product development. Organization Science, 13(4), 442-455.

Carlile, P. R. (2004). Transferring, translating, and transforming: An integrative framework for managing knowledge across boundaries. Organization Science, 15(5), 555-568.

Carlile, P. R., \& Rebentisch, E. S. (2003). Into the black box: The knowledge transformation cycle. Management Science, 49(9), 1180-1195.

Cesaroni, F., \& Piccaluga, A. (2016). The activities of university knowledge transfer offices: Towards the third mission in Italy. The Journal of Technology Transfer, 41(4), 753-777.

Clarysse, B., Wright, M., Lockett, A., van de Velde, E., \& Vohora, A. (2005). Spinning out new ventures: A typology of incubation strategies from European research institutes. Journal of Business Venturing, 20(2), 183-216.

Cohen, W. M., Nelson, R. R., \& Walsh, J. P. (2002). Links and impacts: The influence of public research on industrial R\&D. Management Science, 48(1), 1-23.

Comacchio, A., Bonesso, S., \& Pizzi, C. (2012). Boundary spanning between industry and university: The role of Technology Transfer Centres. The Journal of Technology Transfer, 37(6), 943-966.

Cunningham, J. A., Menter, M., \& Young, C. (2017). A review of qualitative case methods trends and themes used in technology transfer research. The Journal of Technology Transfer, 42(4), 923-956.

D'Este, P., \& Patel, P. (2007). University-industry linkages in the UK: What are the factors underlying the variety of interactions with industry? Research Policy, 36(9), 1295-1313.

Dattée, B., Alexy, O., \& Autio, E. (2018). Maneuvering in poor visibility: How firms play the ecosystem game when uncertainty is high. Academy of Management Journal, 61(2), 466-498.

Debackere, K., \& Veugelers, R. (2005). The role of academic technology transfer organizations in improving industry science links. Research Policy, 34(3), 321-342.

Dollinger, M. J. (1984). Environmental boundary spanning and information processing effects on organizational performance. Academy of Management Journal, 27(2), 351-368.

Dolmans, S. A. M., Shane, S., Jankowski, J., Reymen, I. M. M. J., \& Romme, A. G. L. (2016). The evaluation of university inventions: Judging a book by its cover? Journal of Business Research, 69(11), 4998-5001.

Edmondson, A. C., \& McManus, S. E. (2007). Methodological fit in management field research. Academy of Management Review, 32(4), 1246-1264. 
Eisenhardt, K. M. (1989). Building theories from case study research. Academy of Management Review, 14(4), 532-550.

Eisenhardt, K. M., \& Graebner, M. E. (2007). Theory building from cases: Opportunities and challenges. Academy of Management Journal, 50(1), 25-32.

Filippetti, A. \& Savona, M. (2017). University-industry linkages and academic engagements: Individual behaviours and firms' barriers. Introduction to the special section. The Journal of Technology Transfer, 42(4), 719-729.

Galinsky, A. D., Ku, G., \& Wang, C. S. (2005). Perspective-taking and self-other overlap: Fostering social bonds and facilitating social coordination. Group Processes and Intergroup Relations, 8(2), 109-124.

Gehlbach, H. (2004). A new perspective on perspective taking: A multidimensional approach to conceptualizing an aptitude. Educational Psychology Review, 16(3), 207-234.

Gillespie, A., \& Richardson, B. (2011). Exchanging social positions: Enhancing perspective taking within a cooperative problem solving task. European Journal of Social Psychology, 41(5), 608-616.

Gioia, D. A., Corley, K. G., \& Hamilton, A. L. (2013). Seeking qualitative rigor in inductive research: Notes on the Gioia methodology. Organizational Research Methods, 16(1), 15-31.

Grimpe, C., \& Fier, H. (2010). Informal university technology transfer: A comparison between the United States and Germany. The Journal of Technology Transfer, 35(6), 637-650.

Hawkins, M., \& Rezazade Mehrizi, M. H. (2012). Knowledge boundary spanning process: Synthesizing four spanning mechanisms. Management Decision, 50(10), 1800-1815.

Hayter, C. S., Rasmussen, E., \& Rooksby, J. H. (2020). Beyond formal university technology transfer: Innovative pathways for knowledge exchange. The Journal of Technology Transfer, 45(1), 1-8.

Hoever, I. J., Van Knippenberg, D., Van Ginkel, W. P., \& Barkema, H. G. (2012). Fostering team creativity: Perspective taking as key to unlocking diversity's potential. Journal of Applied Psychology, 97(5), 982-996.

Hoye, K., \& Pries, F. (2009). 'Repeat commercializers', the 'habitual entrepreneurs' of university-industry technology transfer. Technovation, 29(10), 682-689.

Hustad, E. (2007). Managing structural diversity: The case of boundary spanning networks. Electronic Journal of Knowledge Management, 5(4), 399-410.

Huyghe, A., Knockaert, M., Wright, M., \& Piva, E. (2014). Technology transfer offices as boundary spanners in the pre-spin-off process: The case of a hybrid model. Small Business Economics, 43(2), 289-307.

Jemison, D. B. (1984). The importance of boundary spanning roles in strategic decision-making. Journal of Management Studies, 21(2), 131-152.

Jonsson, L., Baraldi, E., \& Larsson, L. E. (2015). A broadened innovation support for mutual benefits: Academic engagement by universities as part of technology transfer. International Journal of Technology Management \& Sustainable Development, 14(2), 71-91.

Kidwell, D. K. (2014). Navigating the role of the principal investigator: A comparison of four cases. The Journal of Technology Transfer, 39(1), 33-51.

Klofsten, M., Heydebreck, P., \& Jones-Evans, D. (2010). Transferring good practice beyond organizational borders: Lessons from transferring an entrepreneurship programme. Regional Studies, 44(6), 791-799.

Krücken, G. (2003). Learning the new, new thing: On the role of path dependency in university structures. Higher Education, 46(3), 315-339.

$\mathrm{Ku}$, G., Wang, C. S., \& Galinsky, A. D. (2015). The promise and perversity of perspective-taking in organizations. Research in Organizational Behavior, 35, 79-102.

Langley, A. (1999). Strategies for theorizing from process data. Academy of Management Review, 24(4), 691-710.

Lee, K. J., Ohta, T., \& Kakehi, K. (2010). Formal boundary spanning by industry liaison offices and the changing pattern of university-industry cooperative research: The case of the University of Tokyo. Technology Analysis \& Strategic Management, 22(2), 189-206.

Leifer, R., \& Delbecq, A. (1978). Organizational/environmental interchange: A model of boundary spanning activity. Academy of Management Review, 3(1), 40-50.

Leifer, R., \& Huber, G. P. (1977). Relations among perceived environmental uncertainty, organization structure, and boundary-spanning behavior. Administrative Science Quarterly, 22(2), 235-247.

Levina, N., \& Vaast, E. (2005). The emergence of boundary spanning competence in practice: Implications for implementation and use of information systems. MIS Quarterly, 29(2), 335-363.

Lin, C. H., Tung, C. M., \& Huang, C. T. (2006). Elucidating the industrial cluster effect from a system dynamics perspective. Technovation, 26(4), 473-482. 
Link, A. N., Siegel, D. S., \& Bozeman, B. (2007). An empirical analysis of the propensity of academics to engage in formal university technology transfer. Industrial and Corporate Change, 16(4), 641-655.

Litchfield, R. C., \& Gentry, R. J. (2010). Perspective-taking as an organizational capability. Strategic Organization, 8(3), 187-205.

Lockett, A., Siegel, D. S., Wright, M., \& Ensley, M. D. (2005). The creation of spin-off firms at public research institutions: Managerial and policy implications. Research Policy, 34(7), 981-993.

Louis, K. S., Blumenthal, D., Gluck, M. E., \& Stoto, M. A. (1989). Entrepreneurs in academe: An exploration of behaviors among life scientists. Administrative Science Quarterly, 34(1), 110-131.

MacGregor, S. P., Marques-Gou, P., \& Simon-Villar, A. (2010). Gauging readiness for the quadruple helix: A study of 16 European organizations. Journal of the Knowledge Economy, 1(3), 173-190.

Mangematin, V., O'Reilly, P., \& Cunningham, J. (2014). PIs as boundary spanners, science and market shapers. The Journal of Technology Transfer, 39(1), 1-10.

Markman, G. D., Phan, P. H., Balkin, D. B., \& Gianiodis, P. T. (2005). Entrepreneurship and universitybased technology transfer. Journal of Business Venturing, 20(2), 241-263.

Markman, G. D., Siegel, D. S., \& Wright, M. (2008). Research and technology commercialization. Journal of Management Studies, 45(8), 1401-1423.

Martin, J., Sokol, B. W., \& Elfers, T. (2008). Taking and coordinating perspectives: From prereflective interactivity, through reflective intersubjectivity, to metareflective sociality. Human Development, 51(5-6), 294-317.

Martinelli, A., Meyer, M., \& Von Tunzelmann, N. (2008). Becoming an entrepreneurial university? A case study of knowledge exchange relationships and faculty attitudes in a medium-sized, researchoriented university. The Journal of Technology Transfer, 33(3), 259-283.

Melkers, J., \& Xiao, F. (2012). Boundary-spanning in emerging technology research: Determinants of funding success for academic scientists. The Journal of Technology Transfer, 37(3), 251-270.

Merton, R. K. (1968). The Matthew effect in science: The reward and communication systems of science are considered. Science, 159(3810), 56-63.

Meyer-Krahmer, F., \& Schmoch, U. (1998). Science-based technologies: University-industry interactions in four fields. Research Policy, 27(8), 835-851.

Miller, K., McAdam, R., \& McAdam, M. (2018). A systematic literature review of university technology transfer from a quadruple helix perspective: Toward a research agenda. R\&D Management, 48(1), 7-24.

Muscio, A., Ramaciotti, L., \& Rizzo, U. (2017). The complex relationship between academic engagement and research output: Evidence from Italy. Science and Public Policy, 44(2), 235-245.

O'Shea, R. P., Allen, T. J., Chevalier, A., \& Roche, F. (2005). Entrepreneurial orientation, technology transfer and spinoff performance of US universities. Research Policy, 34(7), 994-1009.

Perkmann, M., Tartari, V., McKelvey, M., Autio, E., Broström, A., D’Este, P., Fini, R., Geuna, A., Grimaldi, R., Hughes, A., Krabel, S., Kitson, M., Llerena, P., Lissoni, F., Salter, A., \& Sobrero, M. (2013). Academic engagement and commercialisation: A review of the literature on universityindustry relations. Research Policy, 42(2), 423-442.

Perkmann, M., \& Walsh, K. (2008). Engaging the scholar: Three forms of academic consulting and their impact on universities and industry. Research Policy, 37(10), 1884-1891.

Perlow, L. A., Okhuysen, G. A., \& Repenning, N. P. (2002). The speed trap: Exploring the relationship between decision making and temporal context. Academy of Management Journal, 45(5), 931-955.

Ponomariov, B. L. (2008). Effects of university characteristics on scientists' interactions with the private sector: An exploratory assessment. The Journal of Technology Transfer, 33(5), 485-503.

Ponomariov, B., \& Boardman, P. C. (2008). The effect of informal industry contacts on the time university scientists allocate to collaborative research with industry. The Journal of Technology Transfer, 33(3), 301-313.

Pratt, M. G. (2009). From the editors: For the lack of a boilerplate: Tips on writing up (and reviewing) qualitative research. Academy of Management Journal, 52(5), 856-862.

Rice, R.E., Sorcinelli, M.D. \& Austin, A.E. (2000). Heeding new voices: Academic careers for a new generation. Inquiry\# 7. Working Paper Series. New Pathways: Faculty Careers and Employment for the 21st Century.

Rogers, E. M. (2002). The nature of technology transfer. Science Communication, 23(3), 323-341.

Rogers, E. M., Hall, B. J., Hashimoto, M., Steffensen, M., Speakman, K. L., \& Timko, M. K. (1999). Technology transfer from university-based research centers: The University of New Mexico experience. The Journal of Higher Education, 70(6), 687-705. 
Rosenkopf, L., \& Nerkar, A. (2001). Beyond local search: Boundary-spanning, exploration, and impact in the optical disk industry. Strategic Management Journal, 22(4), 287-306.

Rossi, F., Rosli, A., \& Yip, N. (2017). Academic engagement as knowledge co-production and implications for impact: Evidence from knowledge transfer partnerships. Journal of Business Research, $80,1-9$.

Sengupta, A., \& Ray, A. S. (2017). University research and knowledge transfer: A dynamic view of ambidexterity in British universities. Research Policy, 46(5), 881-897.

Shane, S. (2004). Academic entrepreneurship: University spinoffs and wealth creation. Edward Elgar Publishing.

Shane, S., Dolmans, S. A. M., Jankowski, J., Reymen, I. M. M. J., \& Romme, A. G. L. (2015). Academic entrepreneurship: Which inventors do technology licensing officers prefer for spinoffs? The Journal of Technology Transfer, 40(2), 273-292.

Siegel, D. S., Waldman, D. A., Atwater, L. E., \& Link, A. N. (2004). Toward a model of the effective transfer of scientific knowledge from academicians to practitioners: Qualitative evidence from the commercialization of university technologies. Journal of Engineering and Technology Management, 21(1-2), 115-142.

Siegel, D. S., Waldman, D., \& Link, A. (2003). Assessing the impact of organizational practices on the relative productivity of university technology transfer offices: An exploratory study. Research Policy, 32(1), 27-48.

Sorensen, J. A. T., \& Chambers, D. A. (2008). Evaluating academic technology transfer performance by how well access to knowledge is facilitated-Defining an access metric. The Journal of Technology Transfer, 33(5), 534-547.

Stacey, R. (1993). Strategy as order emerging from chaos. Long Range Planning, 26(1), 10-17.

Sterman, J. D. (2000). Business dynamics: Systems thinking and modeling for a complex world. Irwin McGraw-Hill.

Stueber, K. (2008). Empathy. In E. N. Zalta (Ed.), The Stanford encyclopedia of philosophy, Fall, 2008.

Takanashi, C., \& Lee, K. J. (2019). Boundary spanning leadership, resource mobilisation, and performance of university-industry R\&D projects: A study in a Japanese university. Technology Analysis \& Strategic Management, 31(2), 140-154.

Teigland, R., \& Wasko, M. M. (2003). Integrating knowledge through information trading: Examining the relationship between boundary spanning communication and individual performance. Decision Sciences, 34(2), 261-286.

Tracy, S. J. (2010). Qualitative quality: Eight "big-tent" criteria for excellent qualitative research. Qualitative Inquiry, 16(10), 837-851.

Tushman, M. L., \& Scanlan, T. J. (1981a). Characteristics and external orientations of boundary spanning individuals. Academy of Management Journal, 24(1), 83-98.

Tushman, M. L., \& Scanlan, T. J. (1981b). Boundary spanning individuals: Their role in information transfer and their antecedents. Academy of Management Journal, 24(2), 289-305.

Urbano, D., \& Guerrero, M. (2013). Entrepreneurial universities: Socioeconomic impacts of academic entrepreneurship in a European region. Economic Development Quarterly, 27(1), 40-55.

Van de Ven, A. H., \& Poole, M. S. (1995). Explaining development and change in organizations. Academy of Management Review, 20(3), 510-540.

Van Oorschot, K. E., Akkermans, H., Sengupta, K., \& Van Wassenhove, L. N. (2013). Anatomy of a decision trap in complex new product development projects. Academy of Management Journal, 56(1), 285-307.

Walrave, B., Van Oorschot, K. E., \& Romme, A. G. L. (2011). Getting trapped in the suppression of exploration: A simulation model. Journal of Management Studies, 48(8), 1727-1751.

Wright, M. (2014). Academic entrepreneurship, technology transfer and society: Where next? The Journal of Technology Transfer, 39(3), 322-334.

Yin, R. K. (2017). Case study research and applications: Design and methods. Sage Publications.

York, J. G., Hargrave, T. J., \& Pacheco, D. F. (2016). Converging winds: Logic hybridization in the Colorado wind energy field. Academy of Management Journal, 59(2), 579-610.

Youtie, J., \& Shapira, P. (2008). Building an innovation hub: A case study of the transformation of university roles in regional technological and economic development. Research Policy, 37(8), 1188-1204.

Zhang, C., Viswanathan, S., \& Henke, J. W., Jr. (2011). The boundary spanning capabilities of purchasing agents in buyer-supplier trust development. Journal of Operations Management, 29(4), 318-328.

Publisher's Note Springer Nature remains neutral with regard to jurisdictional claims in published maps and institutional affiliations. 